\title{
Polémicos privilegios: dos versiones de la primera sátira conocida en contra de los conversos"
}

La literatura anticonversa del siglo XV se destaca por su diversidad genérica -tratados en prosa, sermones, sátiras poéticas, alegorías, etc.-, pero todas estas obras coinciden en su finalidad de ridiculizar individuos o envilecer la colectividad conversa. Mientras que la mayor parte de estos escritos expresan su animadversión de forma tosca y estereotipada, algunos se distinguen por su forma ingeniosa de diatriba, cobijo retórico que pretende disfrazar los sentimientos moralmente repugnantes que abarcan. Entre ellos se encuentra un curioso documento inédito llamado Privilegio del rey don Juan Segundo concedido a un hombre llamado Hernando, privado suyo, para ser marrano, aunque no lo era por nacimiento, texto manuscrito del siglo XVIII - «Copióse de un libro antiguo de mano»que custodia la Real Biblioteca de Madrid y que se caracteriza por su doble sátira de los conversos y de las patentes nobiliarias. Aquí se edita por primera vez. Pertenece a esta misma tradición el Traslado de una carta de privilegio que el rey don Juan Segundo dio a un hijodalgo, texto que se encuentra en dos manuscritos de la Biblioteca Nacional de Madrid. Sus infortunios editoriales durante más de una centuria justifican aquí una edición fidedigna.

PALABRAS CLAVE: Conversos; sátira; polémica literaria; privilegios reales; siglo XV.

Polemical Privileges: Two Versions of the First-Known Anti-Converso Satire.The anti-Converso literature of the $15^{\text {th }}$ century is noteworthy for its variety of genres -prose treatises, sermons, satirical poetry, allegories, etc.-, but what unites all of these works is their intent to mock individuals or vilify conversos as a whole. While most of

\footnotetext{
* Quisiera aprovechar esta ocasión para dejar constancia de mi agradecimiento a Boston College por haberme concedido una subvención para poder consultar in situ los manuscritos relacionados con el presente trabajo; al personal, siempre amable y eficaz, de la Biblioteca Nacional de Madrid y de la Biblioteca del Palacio Real de Madrid; y a Irma L. Carpenter por su valiosa ayuda en la preparación de este estudio.
}

***dwayne.carpenter@bc.edu 
these works convey their hostility in crude, stereotypical fashion, a few are distinguished by their clever form, a rhetorical cloak designed to conceal the morally repugnant sentiments contained in these texts. Among the latter is a curious, unedited document entitled Privilege that King Juan II granted to a man named Hernando, one of his favored, to become a marrano, even though he was not one by birth. The $18^{\text {th }}$-century manuscript - "copied by hand from an old book"- is housed in the Royal Library of Madrid, and satirizes not only conversos but also patents of nobility. It is here edited for the first time. A work belonging to the same tradition, Transcript of a letter of privilege that King Juan II granted to a hidalgo, is found in two manuscripts in the National Library of Madrid. The editorial misfortunes it has suffered over more than a century warrant its publication here in a reliable edition.

KEYwORDS: Conversos; Satire; Literary Polemics; Royal Privileges; $15^{\text {th }}$ Century.

La polémica contra judíos y conversos que se empuña en Castilla a partir de la segunda mitad del siglo XV se distingue tanto por la acrimonia de las acometidas como por la torcida ingeniosidad literaria de sus autores. En sus dicterios pronunciados contra individuos, igual que en sus invectivas prodigadas sobre comunidades enteras, los escritores, tanto anónimos como célebres, emplean un amplio repertorio de técnicas retóricas y géneros literarios para expresar su animadversión hacia judíos y conversos ${ }^{1}$. Así, por ejemplo, encontramos injuriosos asaltos verbales por poetas cancioneriles, a veces salpicados de vocablos hebreos, como en el caso del famoso «dezir» 501 en el Cancionero de Baena lanzado por fray Diego de Valencia contra el «desprovisto» Juan de España ${ }^{2}$. En otras

${ }^{1}$ Sigue siendo útil K. R. Scholberg, Sátira e invectiva en la España medieval (Madrid, 1971).

2 Para un aprecio general, véanse F. CAntera Burgos, «El Cancionero de Baena: judíos y conversos en él», Sefarad 27 (1967), 71-111; F. Márquez Villanueva, «Jewish 'Fools' of the Spanish Fifteenth Century», Hispanic Review 50 (1982), 385-409; y J. Rodríguez PuÉrtolas, «Jews and Conversos in Fifteenth-Century Castilian Cancioneros: Texts and Contexts», en Poetry at Court in Trastamaran Spain: From the 'Cancionero de Baena' to the 'Cancionero General', E. M. Gerli y J. Weiss, eds. (Tempe, Arizona, 1998), 187-198. En particular, consúltense J. M. SolÀ-Solé y S. E. Rose, «Judíos y conversos en la poesía cortesana del siglo XV: El estilo polígloto de fray Diego de Valencia», Hispanic Review 44 (1976), 371-385 (reimpr. J. M. Solà-Solé, Sobre árabes, judios y marranos y su impacto en la lengua y literatura españolas [Barcelona, 1983], 191-223); N. Rотн, Conversos, Inquisition, and the Expulsion of the Jews from Spain (Madison, Wisconsin, 1995), 168-169; y L. M. GIRÓN-NEGRÓN, «"Muerte, cates / que non 
ocasiones los blancos son personajes políticos, desde Enrique IV, quien se ve calumniado en las Coplas de Mingo Revulgo ${ }^{3}$, hasta el requeteconocido converso Diego Arias de Ávila, ironizado en las Coplas del Provincial ${ }^{4}$. Junto a estos ataques ad hóminem, hay otros muchos encauzados hacia la colectividad conversa y caracterizados por un antisemitismo estereotipado y vulgar. Bajo esta rúbrica se hallan, verbigracia, el anónimo Pleyto de los judios con el perro de Alva ${ }^{5} \mathrm{y}$, sobre todo, el Alborayque ${ }^{6}$, diestro exemplum de despiadado odio hacia judíos y conversos.

El opúsculo de que nos ocupamos ahora también pertenece a estos anónimos polémicos escritos dirigidos mayormente en contra de la esfera conversa sin dejar ilesos a los judíos. Se trata de un privilegio ostensiblemente otorgado por Juan II a un tal Hernando, «privado suyo», cristiano viejo y habitante de Toledo, que solicita al monarca la inaudita concesión de volverse marrano. Aquél se queja de que no puede mejorar, ya que es cristiano viejo, estado que le desfavorece frente a los marranos y sus abundantes privilegios. El rey le otorga enseguida su petición, calificándola de oportuna y conforme con la justicia que otros de su reino le habían reivindicado.

El resto de la sátira, aparte de parodiar agudamente las patentes nobiliarias con un lenguaje legal superfluo y pseudo-sofisticado, consta de un dilatado elenco de los privilegios de que Hernando, ya uno de los «nuevamente fraguados», podrá gozar. Timando impunemente a los cristianos viejos, los marranos siembran «sin temor de Dios y vergüença de las gentes» sentimientos de avaricia y envidia entre los cristianos «lindos» para que éstos se destruyan unos a otros. Gracias a su reciente entrada en la clerecía, los conversos pueden escuchar las confesiones de los cristianos para conocer sus pecados secretos. Se apoderan de los bienes -y las esposas- de los cristianos viejos enviados a la guerra. Como físicos y cirujanos, los marranos traman el deceso de sus adversarios cristianos

cates': El 'discor' 510 de fray Diego de Valencia en el Cancionero de Baena», Revista de Filología Española 82 (2002), 249-272: 250-253.

3 J. Rodríguez Puértolas, Poesía crítica y satírica del siglo XV (Madrid, 1984 ${ }^{3}$ ), 225.

${ }^{4}$ Ibíd., 245.

5 J. E. Gillet, «The Coplas del Perro de Alba», Modern Philology 23 (1925-26), 417-444.

${ }^{6}$ Alborayque, vol. I: Estudio preliminar, edición y notas; vol. II: Facsímil, D. E. CARPENTER, ed. (Mérida, 2005). 
para casarse con sus viudas y sacar provecho de los oficios otorgados por el rey. A pesar de haber recibido el bautismo, los marranos niegan los dogmas de la Iglesia, aseverando que «no ay más mundo [sino] de nacer y morir» ${ }^{7}$. Observan abiertamente los ritos hebraicos, como la circuncisión, el entierro según la costumbre judía y la celebración del sábado, lo mismo que mantienen su predilección por la adafina y la cazuela. Contribuyen económicamente a la sinagoga, a la vez que «rezan» en la iglesia con sus cuadernos de rentas y alcabalas. Descollando la fama de los marranos de hipócritas, Juan II le concede a Hernando la descarada dispensa de «tener [...] dos caras: una para animar e lisongear, e otra para engañar e maltratar e mentir e falsear».

El entorno histórico de esta obra, una versión desconocida hasta ahora de la primera sátira contra los conversos, son los motines encabezados por Pero Sarmiento -nombrado dos veces en esta sátira- en 1449 contra los conversos toledanos ${ }^{8}$. La rauda aparición de la Sentencia-Estatuto inserta de forma tajante el insidioso elemento racial dentro de la polémica entre cristianos y judíos ${ }^{9}$. Las calumnias tradicionalmente imputadas a los judíos ahora se aplican a los conversos, ya que según el concepto de limpieza de sangre, ambos pertenecen a la misma estirpe y comparten radicalmente los

7 J. Caro Baroja, Los judios en la España moderna y contemporánea (Madrid, 1986 ${ }^{3}$ ), vol. I, 511-513; F. MÁrqueZ Villanueva, "'Nasçer e morir como bestias' (Criptojudaísmo y criptoaverroísmo)», en Los judaizantes en Europa y la literatura castellana del Siglo de Oro, F. Díaz Esteban, ed. (Madrid, 1994), 273-293; y D. M. Gitlitz, Secrecy and Deceit: The Religion of the Crypto-Jews (Philadelphia, 1996), 110-115.

${ }^{8}$ Véase la valiosa aportación de H. Pflaum, «Une ancienne satire espagnole contre les Marranes», Revue des Études Juives 86 (1928), 131-150: 133-143.

9 Para el texto de la Sentencia-Estatuto, consúltese T. GonzÁlez Rolán y P. SAquero SuÁrez-Somonte, con la colaboración de P. GonzÁlez SAquero, De la 'Sentencia-Estatuto' de Pero Sarmiento a la 'Instrucción' del Relator. Estudio introductorio, edición crítica y notas de los textos contrarios y favorables a los judeoconversos a raiz de la rebelión de Toledo de 1449 (Madrid, 2012), 13-31. Véanse también E. Benito Ruano, «Don Pero Sarmiento, repostero mayor de Juan II de Castilla. Datos biográfico-documentales», Hispania 17 (1957), 483-504; IDEM, «La Sentencia-Estatuto de Pero Sarmiento contra los conversos toledanos», Revista de la Universidad de Madrid 6 (1957), 277-306; D. NiRENBERG, «El concepto de la raza en la España medieval», Edad Media. Revista de Historia 3 (2000), 39-60; IDEM, «Was there Race before Modernity? The Example of 'Jewish' Blood in Late Medieval Spain», en The Origins of Racism in the West, M. ElaAvFeldon, B. IsAac y J. Ziegler (Cambridge-New York, 2009), 232-264. 
mismos defectos. Esta sátira es el agrio fruto del enfrentamiento, la fusión -y no sólo el reflejo- de la polémica literaria con la contienda política.

Es ésta la primera vez que se edita el Privilegio del rey don Juan Segundo concedido a un hombre llamado Hernando, privado suyo, para ser marrano, aunque no lo era por nacimiento, texto manuscrito - «Copióse de un libro antiguo de mano donde havía algunas cosas notables» (fol. 279')hallado al final de una miscelánea del siglo XVIII, II/715 (R), que custodia la Real Biblioteca de Madrid ${ }^{10}$. A pesar de su interés intrínseco y particular, este privilegio satírico no es el único representante de su género, ya que existen en la Biblioteca Nacional de España en Madrid dos manuscritos de una obra homóloga y bien conocida, el Traslado de una carta de privilegio que el rey don Juan Segundo dio a un hijodalgo. El más antiguo comprende los fols. $29^{\mathrm{r}}-31^{\mathrm{v}}$ de BNE 9175 (M), una miscelánea de 75 obras del siglo XVI «recopiladas y anotadas por el Licenciado Sebastián de Orozco», de las cuales muchas versan sobre cuestiones tocantes a los judíos y conversos ${ }^{11}$. El otro manuscrito en la Biblioteca Nacional del Traslado de una carta de privilegio es la última obra (fols. $172^{\mathrm{r}}-177^{\mathrm{v}}$ ) en una miscelánea del siglo XVIII, BN 13043 (P), cuyos cinco textos están consagrados mayormente a los estatutos de limpieza de sangre ${ }^{12}$. El cotejo de este texto con $\mathbf{M}$ nos

${ }^{10}$ Catálogo de la Real Biblioteca, Tomo XI, Manuscritos, Volumen 1, M. L. LópeZ VidRIERo, dir. (Madrid, 1994), 354-358, núm. 73 (papel), fols. $279^{\mathrm{r}}-282^{\mathrm{v}}$ numerados (320 X 260 / 305 X $202 \mathrm{~mm}$. [fol. 279]). En el margen derecho superior, al lado de la foliación moderna «279», está tachado «21». Tinta marrón. Borrones pequeños, aunque en varios fols. la tinta corrosiva afecta al texto. Letra del s. XVIII. 24-26 11. por fol. En el margen superior izquierdo del fol. $279^{\mathrm{r}}$, apenas visible a causa de la apretada encuadernación, aparece la siguiente nota: «L. 23.| V. 2.0 $»$. Hay dos manos dibujadas en el margen izquierdo al lado de la primera línea de texto después del título. En el lomo se lee: «COLECCION | DE | PRIVILEGIOS | 3 | C.D.E.F.», siendo éste el tercero de siete vols. de privilegios. En el índice al tercer vol. aparece la entrada (núm. 202) para nuestro privilegio bajo «H» («Hernando»). Etiqueta de la biblioteca al pie del lomo: «II/715». En la tapa interior: «Ex libris: BIBLIOTECA | DEL I Rey N. Señor. I [olim] VIII Y 1» y una etiqueta: «715». Encuadernación (s. XIX) en pasta goteada; guardas de mármol inglés.

${ }^{11}$ Inventario general de manuscritos de la Biblioteca Nacional, P. HeRnÁNDEZ Aparicio, ed., vol. XIII (Madrid, 1995), 230-233. El Traslado de una carta de privilegio que el rey don Juan Segundo dio a un hijodalgo -núm. 8 en el Inventario- reza un título algo distinto (¿y escéptico?) en la tabla de materias de la miscelánea: «vna carta de privilegio que dizen que dio el | Rey don juan el segundo a vn hidalgo».

${ }^{12}$ Inventario general de manuscritos de la Biblioteca Nacional, P. HERNÁNDEZ APARICIO y M. ${ }^{a}$ V. Salinas Cano de Santayana, eds., vol. XXI (s. 1., s. a.), 25. Véase también C. del 
permite concluir que, con toda probabilidad, $\mathbf{P}$ es una copia de $\mathbf{M}$, opinión compartida por los dos editores previos de M, Hans Pflaum y Tomás González Rolán y Pilar Saquero Suárez-Somonte ${ }^{13}$. El Traslado de una carta de privilegio ha merecido repetida atención crítica por parte de varios estudiosos, pero, como se apreciará, su suerte editorial no corresponde al atractivo literario-histórico del opúsculo ${ }^{14}$.

Apareció impreso por primera vez el Traslado de una carta de privilegio en 1890 en la heterogénea, y a veces picante, colección de escritos reunidos por Antonio Paz y Melia en la primera serie de Sales españolas, ó agudezas del ingenio nacional ${ }^{15}$. Esta edición inaugural de $\mathbf{P}($ olim Dd. 62) es notable por sus errores de transcripción e idiosincrasia ortográfica, como evidencia la siguiente muestra de las decenas de discrepancias ${ }^{16}$ :

$$
\text { Paz y Melia } \quad P
$$

\begin{tabular}{rll}
\hline Pág. 51, 1.18 & mandásemos & mandassemos \\
Pág. 52, 11. 5-6 & ser siempre & ser de ellos siempre \\
Pág. 54, 1. 14 & Nuestra & vuestra \\
1.16 & estados & estado
\end{tabular}

Valle Rodríguez, Catálogo de Hebraica, impresos, y de Judaica, manuscritos e impresos, de la Biblioteca Nacional de Madrid. Con un apéndice documental de E. Pérez Ferreiro (Madrid, 2004), 328.

13 «Une ancienne satire espagnole», 133; De la 'Sentencia-Estatuto' de Pero Sarmiento a la 'Instrucción' del Relator, 79. Ninguno de los tres manuscritos de la sátira puede fecharse en el siglo XV -el más antiguo es del siglo XVI y los otros dos son copias dieciochescas. Lo más probable es que las dos versiones, $\mathbf{M} / \mathbf{P}$ y $\mathbf{R}$, son copias de textos perdidos, que a su vez se derivan de un arquetipo no existente.

${ }^{14}$ Nótese el excelente resumen y juicio de Scholberg, Sátira e invectiva en la España medieval, 349-352. R. AMran, «Mito y realidad de los conversos castellanos en el siglo XV: El Traslado de una carta-privilegio que el rey Juan II dio a un hijodalgo [sic]», en Judaísmo hispano: estudios en memoria de José Luis Lacave Riaño, E. Romero, ed. (Madrid, 2002), vol. II, 593-605, facilita una amplia síntesis del Privilegio, pero la transcripción de los pasajes de $\mathbf{P}$ que cita no resulta fiable. De hecho, no se justifica que utilice $\mathbf{P}$ para su estudio cuando $\mathbf{M}$ es manifiestamente superior.

15 Colección de Escritores Españoles, vol. 80 (Madrid, 1890), 49-62.

${ }^{16}$ Las páginas se refieren a su edición. 


\begin{tabular}{rll} 
& \multicolumn{1}{c}{ Paz y Melia } & \multicolumn{1}{c}{ P } \\
\hline 1.20 & jarras & aras \\
1.27 & Santa Madre & Madre santa \\
Pág. 57, 1. 11 & hebráica & habrayca \\
1.28 & ó & $\mathrm{e}$ \\
Pág. 58, 1.1 & bagaza & bazaga \\
11. 15-16 & cierta & asi tu \\
Pág. 59, 1. 9 & tovieredes & tuuieredes \\
Pág. 61, 1. 23 & sean & sea
\end{tabular}

La sátira anticonversa fue publicada en 1964 en una segunda edición por Ramón Paz con una ortografía modernizada -aunque no de forma consistente- y ostentando muchos de los errores cometidos por Paz y Melia y la introducción de novedosos fallos de transcripción, como puede observarse ${ }^{17}$ :

$$
\text { Paz } \quad P
$$

\begin{tabular}{rll}
\hline Pág. 25, col. A, 1.26 & ser siempre & ser de ellos siempre \\
1.28 & los & lo \\
col. B, 1.2 & de los marranos & de maranos \\
1.13 & hubiera & ouiera \\
1.29 & mientres & mientes \\
Pág. 26, col. A, 11.19-20 & usura, adobar & usura e adobar \\
1.34 & guardar & guardeis \\
1.35 & obligados & obligado \\
Pág. 26, col. B, 1. 10 & de sacerdotes & de ser sacerdotes \\
Pág. 27, col. A, 1. 35 & cualesquiera & qualesquier \\
col. B, 1. 42 & caballeros, oficiales & Caualleros escuderos \\
& & oficiales
\end{tabular}

1. 43 e

${ }_{17}$ Biblioteca de Autores Españoles, vol. 176 (Madrid, 1964), 23-28. 
Los infortunios editoriales de $\mathbf{P}$ alcanzaron su nadir con la edición del Traslado de una carta de privilegio incluida por Nicolás López Martínez como Apéndice II de Los judaizantes castellanos y la Inquisición en tiempo de Isabel la Católica $^{18}$, un libro cuya aproximación analítica está viciada por las repetidas calumnias antisemitas del autor. Por su parte, el Traslado de una carta de privilegio ostenta más de 40 errores de transcripción de toda índole, volviendo inútil el texto para serios fines académicos.

López Martínez

\begin{tabular}{rll}
\hline Pág. 384, 1. 1 & generación usan & generacion de maranos vsan \\
1.13 & enteder & entender \\
1.30 & podía & podria \\
11. 30-31 & generación, porque & generacion delos maranos por que \\
Pág. 385, 1. 9 & ayudas & ayades \\
1.10 & de la alcaldía & de alcaldia \\
Pág. 386, 1. 7 & bagaza & bazaga \\
1.9 & ninguna & alguna \\
1.15 & otrosí del & otrosi por la presente del \\
1.21 & vida e & via y \\
1.39 & de 2 & en \\
11. $43-44$ & adedante & adelante
\end{tabular}

En 1928, 38 años después de que apareciese la edición de Paz y Melia de la carta de privilegio contenida en $\mathbf{P}$, Hans Pflaum publicó la misma obrita, pero ahora basándose en $\mathbf{M}$, cotejando éste con $\mathbf{P}$ y señalando sus variantes ${ }^{19}$. Por cierto, la edición de Pflaum, y especialmente su valioso comentario histórico, supone un avance en la evolución editorial del Traslado de una carta de privilegio. No obstante, y a pesar del encomiable objetivo de Pflaum de mejorar la edición de Paz y Melia, no sólo no corrige algunos errores de éste sino que incluye al menos 20 fallos de transcripción en su edición de $\mathbf{M} / \mathbf{P}$.

18 (Burgos, 1954), 383-387.

19 «Une ancienne satire espagnole», 144-150. 


\begin{tabular}{|c|c|c|}
\hline & Pflaum & $\mathbf{M}$ \\
\hline Pág. 144, 1.16 & 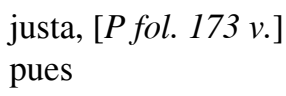 & \\
\hline 11. $18-19$ & condesciendendo & condesçendiendo \\
\hline Pág. 145, 1. 13 & intender & entender \\
\hline 1. 33 & estados [variante] & \\
\hline Pág. 146, 1. 7 & creyen & creen \\
\hline 1. 13 & os & $\operatorname{los}$ \\
\hline Pág. 147, 1. 15 & le & les \\
\hline 11. $22-23$ & como acostumbran & $\begin{array}{l}\text { como lo } \\
\text { acostumbran }\end{array}$ \\
\hline Pág. 148, 1. 10 & $\mathrm{de}_{1}$ & e \\
\hline Pág. 149, 1. 4 & appellido & apellido \\
\hline 1. 23 & caro $[\mathrm{y}]$ amado & caro y muy amado \\
\hline Pág. 150, 1. 4 & predecesores & preçedeçefores \\
\hline 1. 20 & fuerzas & fuerças \\
\hline
\end{tabular}

El esfuerzo más reciente (2012) de editar seriamente el Traslado de una carta de privilegio se debe a Tomás González Rolán y Pilar Saquero Suárez-Somonte. Apareció su edición de la sátira como Apéndice IV en su utilísimo compendio de textos castellanos y latinos referentes a la polémica anticonversa de los siglos XV y XVI ${ }^{20}$. Igual que Pflaum, González Rolán y Saquero Suárez-Somonte utilizan M como texto base de su edición, colacionándolo con $\mathbf{P}$ y la edición de López Martínez, pero curiosamente no con la edición crítica de $\mathbf{M} / \mathbf{P}$ de Pflaum. De nuevo tenemos una edición superior a las anteriores, pero algo empañada por varios deslices en la transcripción de $\mathbf{M}$ (sin tratarse de las variantes de $\mathbf{P}$ ).

${ }^{20}$ De la 'Sentencia-Estatuto’de Pero Sarmiento a la 'Instrucción'del Relator, 79-91. 
González Rolán /

Saquero Suárez-Somonte

\begin{tabular}{rll}
\hline Pág. 83, 1.8 & an & han \\
1.15 & dava sus & dava a sus \\
1.28 & alcanza e & alcança y \\
1.29 & uno de & vno delos de \\
Pág. 84, 1.4 & e dar a logro con renuevo & y dar a logro Renuevo \\
1.13 & obligados & obligado \\
Pág. 87, 1. 12 & bazaha [variante] & baraha \\
1.15 & ninguna & alguna \\
Pág. 88, 1.4 & o & e \\
1.10 & y baratar e mentir. Y & e baratar e mentir. E \\
Pág. 90,1.17 & fuesse & fuese
\end{tabular}

Como puede apreciarse, los previos intentos de realizar una edición crítica del Traslado de una carta de privilegio que el rey don Juan Segundo dio a un hijodalgo (M/P) no han producido resultados que permitan consultar el texto con adecuada confianza. Dada la envergadura históricoliteraria de esta obra, y su obvio interés en relación al Privilegio del rey don Juan Segundo concedido a un hombre llamado Hernando (R), me parece oportuno ofrecer sendas ediciones rigurosamente elaboradas de las dos versiones de este opúsculo caracterizado tanto por sus sentimientos de repulsa hacia los judíos y conversos como por su ingeniosa estrategia retórica $^{21}$.

${ }^{21}$ A pesar de ciertas afinidades léxicas y lingüísticas entre las dos versiones, y notables semejanzas con respecto al contenido, las diferencias entre los dos textos son tantas -y de tanto interés- que una sola edición de los tres manuscritos del Privilegio no resulta aconsejable. En un próximo estudio, examinaré el contenido de las dos versiones, igual que los recursos literarios y retóricos del autor (o de los autores). 
Normas editoriales

He procurado elucidar un texto que, respondiendo a las exigencias científicas del filólogo, al mismo tiempo complazca a un lector interesado más bien en el contenido literario o histórico. Por lo tanto, respeto las peculiaridades ortográficas de los tres manuscritos, por inconsistentes que sean (sotilezas / sutilezas, auctoridad / authoridad, mesmo / mismo), pero para facilitar la lectura introduzco las siguientes modificaciones: sustituyo la $u$ con valor consonántico por la $v$ (uiejo $=$ viejo $)$ y la $v$ con valor vocálico por la $u(v n a=u n a)$, de la misma manera que represento la $j$ vocálica como $i$ (mantenjendo $=$ manteniendo) (no hay ningún caso de $i$ corta con valor consonántico). Mantengo siempre la $y$ (reyno, ymagen). Transcribo la $\int$ como $s$ (softener $=$ sostener $)$. Se ha regularizado el uso de $c$ y $c$ de modo que $c+a, o, u$ representa $/ \mathrm{k} /$ (velar oclusivo sordo) (caro, corte, escuderos); $c+e, i$ y $c+a, o, u$ representan $/ \hat{s} /$ (dorsoalveolar africado sordo) (concejos, ciudad, vergüença, alço, caçuela). No distingo entre ç $+e, i$ (la tendencia de $\mathbf{R}$ y $\mathbf{M}$ ) y $c+e, i$ (la tendencia de $\mathbf{P}$ ) -siempre transcribo $c$ (liçençia $=$ licencia $)$. $-R-$ se representa como $-r r-($ maRano $=$ marrano $)$, y $R-$ y $r r-$ como $r-($ Ranciosos $=$ ranciosos, $r r e y=r e y)$. Desarrollo tácitamente las abreviaturas. La nasal abreviada se desarrolla según su forma predominante $(t \bar{p} o=t i e m p o$, cūplan = cumplan $)$. Reproduzco $x p \bar{i} a n o(s)$ como christiano $(s)$, y $s^{\text {ta }}$ como sancta . No regularizo las conjunciones copulativas: $y$ (la forma dominante en $\mathbf{M}$ y $\mathbf{P}$ ) y $e$ (las dos igualmente comunes en $\mathbf{R}$ ). Separo voces compuestas como enla = en la, delos = de los -mas dejo intactas formas como desdel y dello-, a la vez que uno palabras como quexando vos = quexándovos. En el cotejo de los manuscritos, en general no se incluyen variantes ortográficas o modernizaciones (dezir / decir, ossario / osario, viuieredes / bivieredes, e / y). Regularizo minúsculas y mayúsculas según el uso moderno y sigo las normas académicas con respecto a la puntuación y la acentuación. Encierro entre corchetes toda añadidura editorial en el texto y señalo en las notas toda corrección o interpolación mía. 


\section{$[\mathrm{cruz}]^{22}$}

[fol. $29^{r} \mathbf{M}$, fol. $\left.173^{r} \mathbf{P}\right]$ Traslado de una carta de privilegio que el rey don Juan II dio a un hijodalgo ${ }^{23}$.

Don Juan, por gracia de Dios rey de Castilla y de León, etc. Por quanto vos ${ }^{24}$, Juan, me fezistes relación quexándovos mucho que por vuestro nascimiento aver sido de la generación de los ranciosos, que quiere dezir christianos viejos lindos, no podíades medrar cosa alguna ni vos aplicar a fazer las cosas, artes, sotilezas y engaños y maldades que, sin temor de Dios y vergüença de las gentes, fazen y tratan los de la generación de los hebreos que son legítimos, que quiere dezir marranos ${ }^{25}$, nuevamente fraguados por nuestros pecados. Por tanto que nos suplicávades y pedíades por merced que, usando con vos de clemencia y piedad, vos mandásemos legitimar y dar licencia para ser tal marrano y poder usar de las sutilezas, artes, tratos y engaños de que los dichos marranos, sin temor de Dios y vergüença de las gentes, usan y se aprovechan. E nos, veyendo ser cosa justa, pues $\left[f o l .173^{v} \mathbf{P}\right]$ de otra ${ }^{26}$ manera entre ellos no podríades bivir sin ser de

${ }^{22}$ Sólo en $\mathbf{M}$. En el ángulo superior izquierdo de $\mathbf{M}$ hay una nota parcial de la misma época del texto (se ha perdido casi toda la primera línea salvo unos fragmentos de algunas letras como resultado de un recorte de la hoja): «por algun cristiano viejo | hijo dalgo que no medrava».

${ }^{23}$ Aparece dos veces este título en $\mathbf{P}$, la primera vez solo (fol. $172^{r}$ ); la segunda vez para encabezar el texto mismo del privilegio (fol. $173^{r}$ ). En la tabla de materias de $\mathbf{P}$, de otra mano, se encuentra la siguiente entrada, aquí transcrita por primera vez: «Carta Satirica de [subrayado] Privilegio que el Rey D. Juan el II. | dio á un Hijodalgo, legitimandole para que en adelante $\mid$ pudiese ser de la ralea y generacion de los Hebreos legi- | timos, que quiere decir marranos, y dandole lisencia y facul- | tad para que sin temor de Dios, ni verguenza pudiese fa- | bricar y usar qualesquiera maldades y engaños.... [fol.] 173.».

${ }^{24}$ vos] Está precedido por una «p» tachada.

${ }^{25}$ marranos] $\mathbf{P}$ casi siempre escribe «marano(s)», quizá influido por la ortografía de $\mathbf{M}$ : «maRano(s)», aunque en algunas ocasiones reproduce la «-R-» de $\mathbf{M}$ como «-rr-»; e.g., «maRano(s) / marrano(s)» (fol. $30^{\mathrm{v}} \mathbf{M}$, fol. $176^{\mathrm{r}} \mathbf{P}$ ); «baRida / barrida» (fol. $30^{\mathrm{r}} \mathbf{M}$, fol. $\left.174^{\mathrm{v}} \mathbf{P}\right)$

${ }^{26}$ de otra] A primera vista, $\mathbf{M}$ parece rezar «de fotra»; no obstante, una lectura atenta de todo el texto demuestra que al principio de la obra el copista incorpora una especie de «[i》 estilizada, sin valor fonético alguno, en una variedad de contextos, pero sobre todo delante de «o». Como resultado, en dos ocasiones en esta misma oración el copista de $\mathbf{P}$ introduce lecturas inequívocas, si bien erróneas: «desotra» y «sotros». Luego parece que se dio cuenta de su fallo, o al menos de una ambigüedad ortográfica, puesto que 
ellos siempre engañado, e considerando que algunos otros de nuestros reynos nos lo han pedido y suplicado, condescendiendo a vuestra suplicación y demanda, tovímoslo por bien.

Por ende, por la presente, por vos fazer bien y merced, vos legitimamos y avemos por legitimado para que de aquí adelante, en todo el tiempo de vuestra vida, podades ser e seades tal marrano y de la ralea y generación de los marranos en vuestras obras y tratos, bien así como si en ella mesma oviérades nascido y os oviérades criado. E vos damos licencia y auctoridad y facultad para que, sin temor de Dios ni vergüença de las gentes, podades fazer e intentar, usar y fabricar qualesquier sutilezas, maldades, engaños y lisonjas e otras cosas semejantes, de las quales todos los de la dicha generación de marranos usan y se aprovechan, según su constelación y nascimiento los inclina. Esto sin pena para quanto en este mundo solamente. Para lo qual, nos, por la presente carta vos alçamos y quitamos qualquier vergüença, bondad y honestidad y temor que de Dios Nuestro [ $f \circ$. $29^{v} \mathbf{M}$ ] Señor y de las gentes tengáis, la qual vergüença y honestidad damos por ninguna y de ningún valor y fecto ${ }^{27}$, bien ansí como si nunca en vos ni en vuestra cara la oviera avido. Por virtud de lo qual, vos damos ${ }^{28}$ poder para que poda[fol. $174^{r} \mathbf{P}$ ] des gozar y gozedes de la buena andança y venturas y parentescos y amistades para [quanto] ${ }^{29}$ en este mundo, según dicho es, que todos los de la dicha generación de los marranos han ${ }^{30}$ y gozan, según su constelación y nascimiento.

E así mismo para que si con algún señor o señores de aquí adelante biviéredes, presumades, sin temor ni vergüença, de los engañar y dar a entender que la moneda vale mucho, por que por ello se fagan cobdiciosos y desordenados, y los trabajadores y los que poco pueden se pierdan y no ganen el mantenimiento

abandona su anterior práctica caligráfica, y en cambio ahora escribe «de otra» $\mathrm{y}$ «o», en lugar de «desotra», «so», etc. Las ediciones de Paz, Paz y Melia, y López Martínez, se basan exclusivamente en $\mathbf{P}$ y todos mantienen la «S» superflua de «desotra», pero no la de «sotros». Los editores de ambos P y M son Pflaum y González Rolán-Saquero SuárezSomonte. Aquél tiene «desotra» en su edición de $\mathbf{M}$, pero no «sotros», mientras que éstos reproducen ambas lecturas de $\mathbf{P}$ en su edición de $\mathbf{M}$. Luego, todos dejan de reproducir la peculiaridad estilística introducida por $\mathbf{P}$.

27 fecto] corr. de «fecho» $\mathbf{P}$; cf. effecto $\mathbf{R}$.

28 damos] corr. de «mandamos» («man» tachado) $\mathbf{P}$.

29 Pflaum añade «quanto», basándose en la susodicha lectura análoga: «Esto sin pena para quanto en este mundo solamente». Aunque «quanto» no aparezca en ninguno de los tres MSS, a mi juicio se justifica la enmienda.

${ }^{30}$ han] Trazada de nuevo la palabra sobre el original con el intento (¿por parte del copista?) de aumentar la legibilidad de la palabra. 


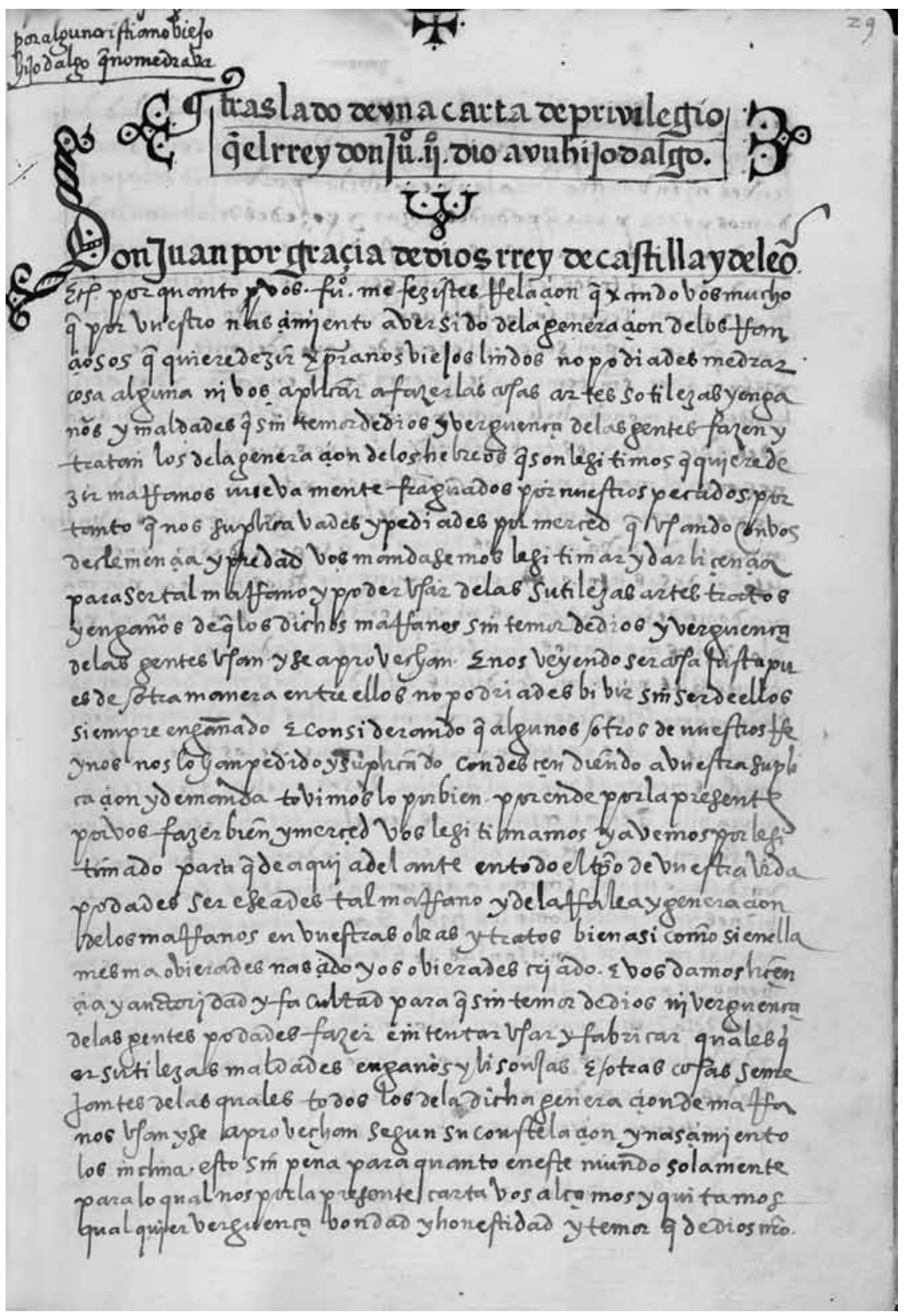

Fig. 1: (C) Biblioteca Nacional de España, Madrid, ms. 9175, fol. 29r. 


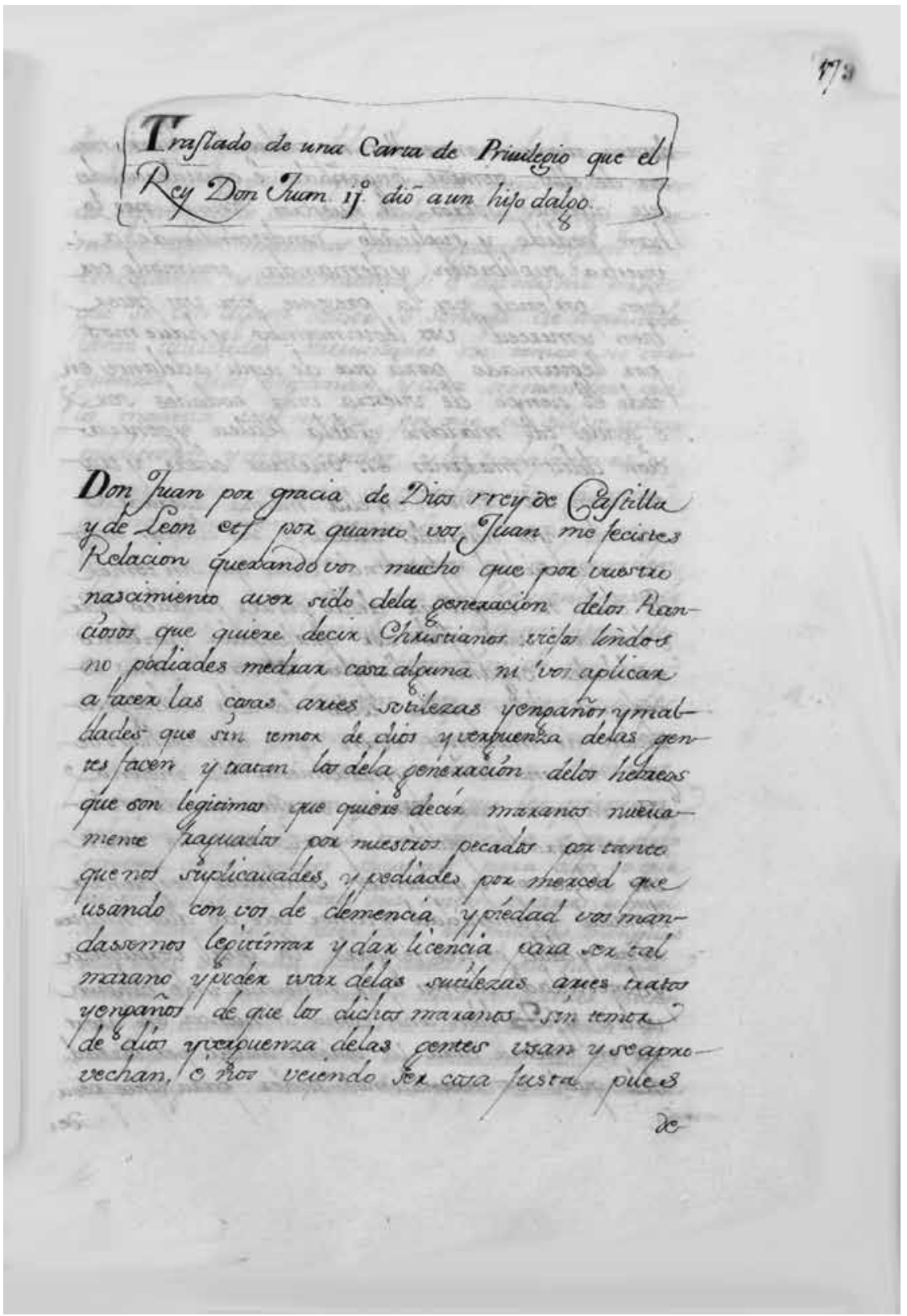

Fig. 2: () Biblioteca Nacional de España, Madrid, ms. 13043, fol. 173r.

SEFARAD, vol. 72:2, julio-diciembre 2012, págs. 295-324. ISSN: 00037-0894. doi: 10.3989/sefarad.012.009 
necesario, $\mathrm{e}^{31}$ para que con la cobdicia no paren mientes ni se acuerden ${ }^{32}$ de los castigos y consejos que un rey antepassado dava a sus fijos, diziendo que se guardasen de no fazer ${ }^{33}$ tesor[er] ${ }_{0}{ }^{34}$ de sus tesoros $y^{35} \mathrm{de}^{36}$ tomar a ninguno de los fariseos por mayordomo de sus faziendas ni por consejero de sus consejos, porque los dichos marranos, fariseos, hebreos y saduceos eran y son gentes que les pornían cobdicias desordenadas muy dañosas, e que de lo propio de los señores sacavan para ellos lo que avían menester para sus tratos e artes, lo qual sería causa de los fazer caer en muchas menguas y en malquerencia de sus pueblos. E que no sería maravilla que estas cosas e otras semejantes fiziesen, pues que trataron la muerte a Nuestro Señor y Redemptor Jhesú Christo, su verdadero criador, sin causa alguna, aviéndoles fecho tantos bienes y mercedes, [fol. $174^{v}$ P] como les fizo.

E ansí mismo podades alcançar y alcancedes con lisonjas, sotilezas e intereses tanto provecho y ganancia quanto alcança y podría alcançar cada uno de los de la dicha generación de los marranos, porque nuestra ${ }^{37}$ merced y voluntad es, y a nuestro servicio conviene y cumple, que no seades menos ni de menor ${ }^{38}$ estado ni tengades más vergüença que ellos tienen. Y tenemos por bien, y es nuestra merced, que la debisa de vuestras armas sea de aquí adelante jarras ${ }^{39}$ de Sancta María y flores de lis.

E otrosí que podades sin pena alguna $\left[\right.$ fol. $\left.30^{r} \mathbf{M}\right]$ cohechar y dar a logro, renuevo e usura, e adobar la casa de la Torá e adorar su ymagen, e casar con vuestras parientas e tener la opinión y malvada intención que tienen e mantienen los dichos marranos, no creyendo, como no creen, lo que la Madre Sancta Iglesia cree y tiene y predica, e lo que en el Credo se canta y contiene, que

31 e] Hay una letra, quizá una «e» minúscula, tachada justo antes de la «E» del MS.

32 acuerden] El copista parece haber empezado a escribir una «q» en lugar de una «c», pero el resultado es más bien «acuerden». $\mathbf{P}$ reza «aquerden».

33 fazer] Pflaum enmienda a «fazer[los]», la lectura corr. hallada (quizá añadida) en $\mathbf{P}$, pero no lo indica en sus notas o variantes.

34 tesor[er]os] MS: tesoros; tesoreros (corr. de «tesoros») P; cf. tesoreros R. La enmienda se justifica también por el paralelismo de los vocablos: «tesor[er]os_- tesoros / consejeros-consejos».

35 y de] Escrito por encima de «nj».

36 y] ni $\mathbf{P}$.

37 nuestra] vuestra $\mathbf{P}$. La toscamente escrita «n» de $\mathbf{M}$ fácilmente podría confundirse con una «u».

38 menor] menos MS, P; cf. menor R. Por razones de estilo y sentido, adopto la lectura de $\mathbf{R}$.

39 jarras] aras $\mathbf{P}$; cf. jarras $\mathbf{R}$. 
verdaderamente es nuestra fe, e que no ay otro mundo sino nascer y morir, como los dichos marranos tienen y afirman contra verdad.

E así mismo podades guardar el sábado y trabajar el domingo y las otras fiestas que la Iglesia manda guardar, y de tal manera guardéis los dichos sábados que no seáis obligado a fazer obra alguna en alguno de ellos, dexando de antenoche los candiles limpios y adereçados, con sus torcidas ${ }^{40}$ limpias, y barrida la casa e lavados los platos y escudillas y las otras cosas necesarias al servicio de ella, e dexando guisado desdel viernes lo que [ fol. $\left.175^{r} \mathbf{P}\right]$ avéis de comer el sábado, ora sea adafina ${ }^{41}$ o caçuela o otro qualquier manjar, así como lo usan y costumbran hazer todos los de la dicha generación de los marranos.

E por la presente mandamos a todos los dichos marranos y a qualquier de ellos, que vos reciban en sus concilios, juntas, ayuntamientos e confederaciones, e ayades e trabajedes aver ${ }^{42}$ y alcançar con todo arte e sotileza ${ }^{43}$ e lisonja qualquier oficio real, así de alcaldía $[y]^{44}$ regimiento, como de juradería y escrivanía pública, para que por virtud de los dichos oficios podades gozar y gozedes de los propios y rentas de la cibdad, villa o lugar donde así fuéredes proveído del dicho oficio, engañando a los christianos viejos lindos y ranciosos con palabras sotiles y engañosas, dando ocasión a que se maten los unos con los otros.

E otrosí que podades vos, e los que de vos de aquí adelante procedieren, procurar de ser sacerdotes y curas de ánimas debaxo de engaño y cautela para que, oyendo de penitencia a los christianos viejos lindos, sepáis e sepan los pecados secretos de ellos.

E así mismo damos licencia a vos e a los dichos vuestros descendientes para que podáis ser boticarios, físicos y zurujanos, e so color de curar e procurar por la salud de las enfermedades del cuerpo de qualquier christiano viejo, trabajéis e procuréis, como trabajan e procuran $\left[\right.$ fol. $\left.30^{v} \mathbf{M}\right]$ todos los de la dicha generación de los marranos, de matar y apocar a los christianos viejos, así por el odio y enemistad que les tienen, como $\left[\right.$ fol. $\left.175^{v} \mathbf{P}\right]$ por casar con las mugeres de aquellos christianos viejos que matan por tragar sus bienes y faziendas y ensuziar y manzillar la sangre limpia. E de aquéllos que por vuestra buena diligencia passaren de esta vida, podades procurar de aver los oficios de los tales

40 torcidas] tizadas $\mathbf{P}$.

41 adafina] Subrayado.

${ }^{42}$ aver] a ver P. P separa insólitamente las letras del verbo «aver», produciendo así una lectura equívoca, que reproducen González Rolán-Saquero Suárez-Somonte.

43 sotileza] MS: soltileza.

${ }^{44}$ [y]] Om. también por $\mathbf{P}$, pero cf. el pasaje análogo en $\mathbf{R}$ : «assí de alcalde como de regimiento». Tanto el sentido como el estilo paralelo de la oración justifican la introducción de la conjunción, añadida tácitamente por Pflaum. 
defunctos, todo a fin que lo aya y alcance otro de la línea y generación de los dichos marranos, hebreos o de otra semejante stirpe o ralea.

E otrosí vos damos licencia para que, sin ningún temor, como lo acostumbran a fazer los dichos marranos, podades avisar a los susodichos de qualquier secreto o pecado que qualquier christiano viejo en confisión, o fuera della, vos aya dicho y manifestado para que los dichos marranos acusen al dicho christiano viejo del dicho pecado o delito. E puesto e acusado ante la justicia, él no lo pueda negar, pues lo tiene confessado, e confessándolo, pierda todos sus bienes, e pidiendo merced de ellos, se los toméis, como muchas vezes ha acaescido.

E así mismo vos, e los que de vos vinieren, podades e puedan aprender sciencia habrayca en la sinoga ${ }^{45}$ de los judíos, o en otra qualquier parte donde la dicha sciencia se enseñare o leyere.

E así mismo podades fazer e tener vuestro enterramiento en el ossario de los judíos y enterraros en tierra virgen y acompañar el cuerpo o cuerpos de los judíos que fallescieren fasta el dicho ossario. E bueltos a casa del defuncto, podades fazer las guayas que acostumbran fazer. E después de aver fecho las dichas guayas e cerimonias judaycas, podades comer de los manjares [fol. $176^{r} \mathbf{P}$ ] que los judíos y marranos comieren, asentándoos con ellos en el suelo, según los susodichos lo usan y acostumbran fazer.

E así mismo vos damos licencia para que en las fiestas y regozijos solenes de los judíos e marranos podades estar e ser presente ${ }^{46}$, e allí beváis del vino de la baraha ${ }^{47}$ que ellos beven.

E así mismo que fingidamente podades entrar en la iglesia y lugares sagrados sin alguna devoción, llevando, en lugar de oras o psalterio, el libro [d] $\mathrm{e}^{48}$ memoria de las rentas e alcavalas que tenés arrendadas a vuestro cargo, fingendo que rezáis los psalmos penitenciales, como lo fazen y acostumbran muchos de la dicha generación de los marranos.

45 sinoga] sinagoga $\mathbf{P}$; cf. synoga $\mathbf{R}$.

46 presente] MS: presentes (con la «s» final tachada).

47 baraha] bazaga P. Sin duda alguna se refiere al vocablo hebreo ברכה, «bendición», ya señalado por Pflaum.

48 [de]e] e MS, P. Pflaum lo corr. tácitamente a «de». Me parece acertada su corrección, ya que el término «libro de memoria» se emplea en el siglo XVI no sólo en el sentido religioso de despertar el alma, sino también para referirse a un libro de cuentas. Véase, por ejemplo, «Testamento de don Lorenzo de Cepeda a la Santa», en Silverio de Santa Teresa, C. D., ed., Obras de Santa Teresa de Jesús (Burgos, 1923), tomo VIII, 504519: «Item, declaro que los bienes muebles que tengo están en un memorial firmado de mi nombre, que está metido en el libro, en el cual y en otro libro de memoria, que están en mi escritorio, está lo que debo e lo que me deben...» (consultado en CORDE, Corpus diacrónico del español, http://www.rae.es, julio de 2012). 
E mandamos que ninguno sea $\left[\right.$ fol. $\left.31^{r} \mathbf{M}\right]$ osado de vos ${ }^{49}$ desafiar ni amenazar, por que no se pueda dezir ${ }^{50}$ por vos: «¿quién dio armas al marrano, sino vida baratera y de trapaças?»

E otrosí por la presente, del caso mayor al menor ${ }^{51}$ inclusive, de nuestro propio motu, cierta ${ }^{52}$ sciencia y poderío real absoluto de que en esta parte queremos usar e usamos, vos perdonamos la pena de este mundo de qualesquier juramentos falsos, mentiras $[\mathrm{e}]^{53}$ falsedades que dixéredes y afirmáredes para engañar a los christianos viejos, e por lo que a vos e a vuestro interese e de vuestros parientes cumpliere, todavía manteniendo e llevando la vía y horden que mantienen y llevan los otros de la dicha generación de los marranos.

E otrosí vos damos licencia para que de aquí adelante podades tener y tengáis ${ }^{54}$ dos caras: la una para mirar $y^{55}$ lisonjear, y la otra ${ }^{56}$ para engañar e baratar e mentir.

E así mismo para que vos podades baptizar $\left[\right.$ fol. $\left.176^{v} \mathbf{P}\right]$ y baptizedes de nuevo, para que por virtud del dicho baptismo os ${ }^{57}$ podades circuncidar ${ }^{58}$ e retajar, según que los dichos marranos, judíos, hebreos e saduceos lo usan y acostumbran fazer, nombrándose de aquella ley que sostienen e mantienen y entienden sostener y mantener. E podades tomar el apellido del linaje que quisiéredes e por bien tuviéredes, mudándovos el nombre de vuestros antepassados marranos por ser ${ }^{59}$ conoscido, tomando nombres de christianos por cumplir con el mundo y engañar las gentes, y en secreto llamándovos de nombre hebrayco, como lo fazen los otros marranos, hebreos por que en todo y por todo guardéis e cumpláis e uséis la vía y horden que usan y guardan los de la dicha línea bulliciosa que es de

${ }^{49}$ de vos] añadido (¿por otra mano?) $\mathbf{P}$.

${ }^{50}$ dezir $+\left\langle\mathrm{q}^{\mathrm{i}} »\right.$ tachado, probablemente anticipando «quien».

${ }^{51}$ menor] corr. de «menos» $\mathbf{P}$.

52 cierta] asi tu $\mathbf{P}$.

${ }^{53}$ [e]] Om. también en $\mathbf{P}$. En una serie de sustantivos como ésta, M normalmente incluiría una conjunción aquí.

${ }^{54}$ tengáis] tengades $\mathbf{P}$. A veces $\mathbf{P}$ luce formas arcaizantes frente a las lecturas de $\mathbf{M}$.

55 mirar y] añadido $\mathbf{P}$.

56 otra] MS: otro.

${ }^{57}$ os] Om. $\mathbf{P}$.

58 circuncidar] corr. de «circunadar» $\mathbf{P}$.

59 por ser] Pflaum intercala «no», observando que no aparece ni en $\mathbf{M}$ ni en $\mathbf{P}$. Efectivamente, la oración tiene más sentido sin la negación, dado que el autor quiere hacer hincapié en que los antiguos apellidos de los conversos indican claramente su ascendencia judía, y por eso quisieron cambiarlos. 
los marranos. E podades fazer e fagades ${ }^{60}$ todas las solenidades, ofertas, fablas e reverencias falsas e fingidas que por fazer vuestros intereses cumple fueren necesarias e se requieren fazer.

E por quanto nos ${ }^{61}$ ha sido fecha relación que Pedro ${ }^{62}$ Sarmiento, nuestro repostero ${ }^{63}$ mayor e de nuestro Consejo y asistente en la cibdad de Toledo, es vuestro enemigo, según que por algunos de los dichos marranos nos ha sido quexado, mandamos que el dicho Pedro Sarmiento ni alguno de su linaje no conozca de vuestros pleitos ni de causa alguna que contra vos fuere movida o se moviere de aquí adelante, ni tengan que entender ni se entrometan en las cosas que a vos tocaren.

E por la pre- $\left[\right.$ fol. $\left.31^{v} \mathbf{M}\right]$ sente mandamos al príncipe don Enrrique, nuestro muy caro y muy amado fijo, so pena de nuestra paternal maldición, y al maestre de Santiago, condestable de Castilla, e a los duques, condes, marqueses, cavalleros, ricoshombres, maestres de las hórdenes, comendadores, alcaides de los castillos e casas fuertes e a los ${ }^{64}\left[\right.$ fol. $\left.177^{r} \mathbf{P}\right]$ del nuestro Consejo, oydores de las nuestras audiencias, alcaldes, alguaziles e otras justicias qualesquier de la nuestra casa e corte e chancillerías ${ }^{65}$, e a todos los concejos, corregidores, alcaldes, alguaziles, regidores, jurados, cavalleros, escuderos, oficiales y hombres buenos que agora son o serán de aquí adelante, e a otras qualesquier personas, nuestros súbditos y naturales de qualquier estado, condición, prehemi[n]encia ${ }^{66}$ o dignidad que sean, que guarden y cumplan y executen e fagan guardar, cumplir y executar esta nuestra carta de merced e lo en ella contenido. E contra ella ni parte de ella no ${ }^{67}$ vayan ni pasen ni consientan ir ni passar agora ni en tiempo alguno ni por alguna manera so pena de la nuestra merced, no embargantes qualesquier leyes, fueros e derechos, hordenamientos, cartas o privilegios que los reyes nuestros predecesores ${ }^{68}$ cerca de lo susodicho fiziesen, ordenasen o diesen, o de aquí adelante fuere fecho y ordenado contra lo en esta nuestra carta contenido o parte de ello. Ca nos de nuestro propio motu, cierta sciencia y poderío real e absoluto de que en esta parte queremos usar y usamos, dispensamos con ello e con cada

\footnotetext{
${ }^{60}$ fagades] ¿Corr. la «e»?

${ }^{61}$ nos] Corr. (¿por mano posterior?) de «vos» $\mathbf{P}$.

${ }^{62}$ Pedro] ¿Corr. la «d»?

${ }^{63}$ repostero] «re» corr. $\mathbf{P}$.

${ }^{64} \operatorname{los}+\operatorname{los} \mathbf{P}$.

${ }^{65}$ chancillerías] La primera «a» corr., probablemente de «n».

${ }^{66}$ prehemi[n]encia] MS: prehemjençia.

${ }^{67}$ no] Corr., probablemente de «nos» $\mathbf{P}$.

${ }^{68}$ predecesores] MS: preçedeçesores.
} 


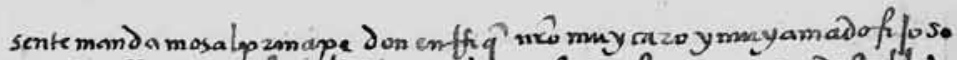

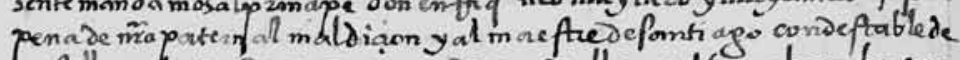

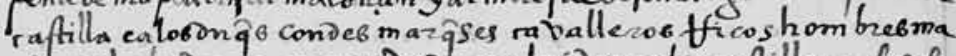

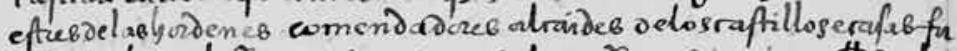

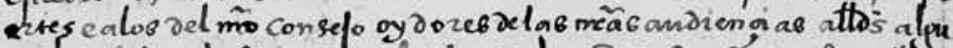

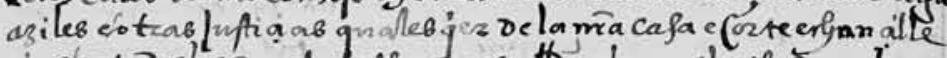

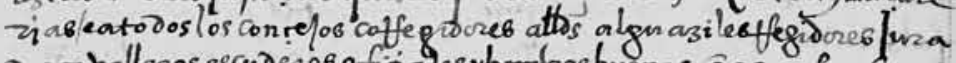
doc raballeros escurieros ofia alesyhombes buenos gagora fon bsera

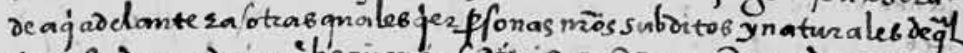

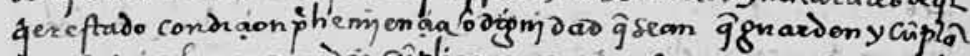
yeve inten e fapom ginidair aupliz yexe antar efta mia rastade mez red docrella contenj o scontza ellam partede ella no bayan in pafen

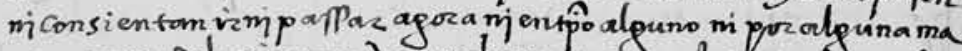
nera sopenarda ma mezrd no embazpantes gnales griner teyce fre 206 crezergos hozdenamientos rantalopibilegios ôlosffeyeb mos puerede refonce resra delofufo arigo fiziesen ordenasen/otiesen o deaqui

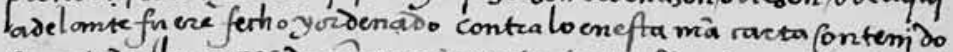
6 partedecto canos demo propio motu rienta fạen riaypodecio feal, eabsolutodegen efta park gremos ofar ybfamosis penfamoscon ello e con rava af a epácter edlo elo recogamos yabroghmos yramos

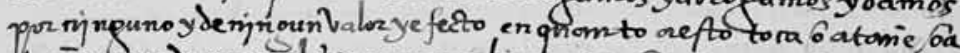

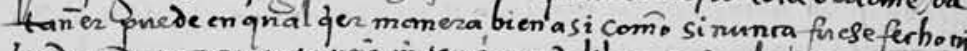

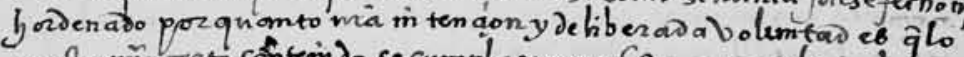

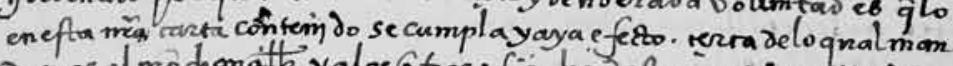
ramos almo hanath yalos o twos ofigales q ftom a siften yefegiden,

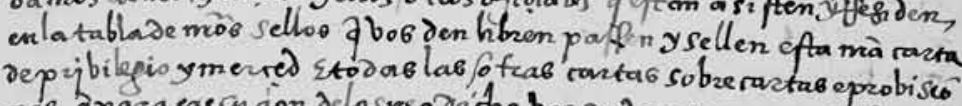
neb gpaza execon dion delosves oritho bos conbengan emeneflezbosfea

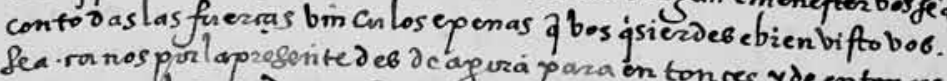
Lea.ranos pur apreserite deb dcaguza yaza on ton res y deenton res

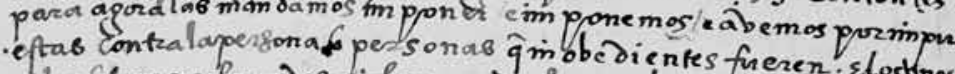
mlos otios no fagadeb wi fapan endeal por alguna manerasostos

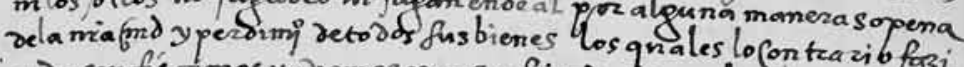
endo con fis ramos yabemos por cosfis rados parala ma con zib fazi Efisco.rada s? on tpo de ptaprobision si ellapobio bers adera mete / abia judioson captilla

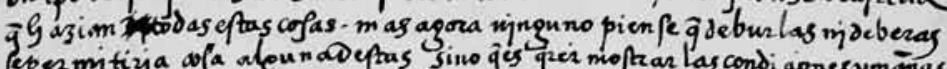
apermitiza of a aleun owe prus sino ges gzer nioptzar las condi a anesymañas jeinan lasjurits con los epi anos

Fig. 3: (C) Biblioteca Nacional de España, Madrid, ms. 9175, fol. 31v. 
cosa e parte de ello, e lo derogamos y abrogamos y damos por ninguno y de ningún valor y efecto en quanto a esto toca o atañe o atañer puede en qualquier manera, bien así como si nunca fuese fecho ni hordenado, por quanto nuestra intención y deliberada voluntad es que lo en esta nuestra carta contenido se cumpla y aya efecto.

Cerca de lo qual mandamos al nuestro chanciller y a los otros oficiales que están, asisten y residen en la tabla de nuestros sellos, que vos den, libren, passen y sellen esta nuestra carta de privilegio y merced, e todas las [fol. $177^{v} \mathbf{P}$ ] otras cartas, sobrecartas e provisiones que para execución de lo susodicho vos convengan e menester vos sean ${ }^{69}$, con todas las fuerças, vínculos e penas que vos quisierdes e bien visto vos sea. Ca nos por la presente, desde agora para entonces y de entonces para agora, las mandamos imponer e imponemos e avemos por impuestas contra la persona o personas que inobedientes fueren. $\mathrm{E}$ los unos ni los otros no fagades ni fagan ende ál por alguna manera so pena de la nuestra merced y perdimiento de todos sus bienes, los quales, lo contrario faziendo, confiscamos y avemos por confiscados ${ }^{70}$ para la nuestra cámara e fisco. Dada, etc. ${ }^{71}$.

69 sean] sea $\mathbf{P}$.

70 confiscados] La «n» está casi borrada por una mancha de tinta.

71 Al final del documento se lee la siguiente nota: «ojo [en el margen izquierdo] en tiempo de esta probision si ella se dio berdaderamente/ avia judios en castilla | que hazian [dos o tres letras tachadas] todas estas cosas. mas agora njnguno pienfe que de burlas nj de beras $\mid$ se permjtirja cosa alguna destas sino que es querer mostrar las condiçiones y mannas [también posible: «maneras»] | que tenjan los judios con los christianos». 
[fol. $279^{r} \mathbf{R}$ ] Privilegio del rey don Juan Segundo concedido a un hombre llamado Hernando, privado suyo, para ser marrano, aunque no lo era por nacimiento. Copióse de un libro antiguo de mano donde havía algunas cosas notables.

Don Juan, por la gracia de Dios rey de Castilla, de León, etc. Por quanto vos, Hernando, vezino de Toledo, me fezistes relación quexándovos mucho que por buestro nacimiento haver sido de la generación de los ranciosos, que quiere dezir de los christianos lindos, alias viejos, no podíades medrar ni abarcar ni bos applicar ni hazer las cosas, e menos de ${ }^{72}$ usar las artes y sotilezas, engaños y maldades que, sin temor de Dios ni vergüença de las gentes, hazen y tratan los de la generación de los hebreos que son legítimos, que quiere dezir marranos, nuevamente fraguados, franqueados por nuestros grandes peccados. Por ${ }^{73}$ tanto, me ${ }^{74}$ supplicávades y pedíades por merced que, usando con vos de clemencia e piedad, vos mandasse legitimar e dar licencia para usar e perseverar sin temor de Dios ni vergüença de las gentes, como dicho es. E yo, viendo me pedíades justicia, e porque me lo supplicaron e pidieron por merced algunos de los mis reynos y señoríos, túvelo por bien.

Por ende, por la presente, por vos fazer bien y merced, vos ligitimo e hago legítimo para que de aquí adelante, y en toda buestra vida, seades de la dicha generación de los marranos, bien assí como si en ella huviérades nacido. E vos doy licencia e facultad e auctoridad para que, sin temor de Dios ni vergüença de las gentes, podades hazer y sacar e interpretar qualesquier soti- [fol. $279^{v} \mathbf{R}$ ] lezas, maldades, engaños e otras qualesquier cosas, e cada una de ellas ${ }^{75}$ que la generación de los marranos puedan e devan hazer, según su constelación y nacimiento. Y que por la presente, e con ella, vos alço e quito caso e anulo qualquier vergüença, bondad e honestidad que ahora en vos ay, e si la huviere en algún tiempo, la casso e revoco e doy por ninguna e de ningún valor y effecto, bien assí como si en buestro rostro e persona huviera sido havida ni puesta. $\mathrm{E}^{76}$

72 de] Dado el tamaño diminuto de estas dos letras, y el espacio limitado entre «menos»y «usar», es posible que se insertó posteriormente la preposición.

${ }^{73}$ Por] Escrito enteramente en el margen izquierdo.

${ }^{74}$ me] Cf. «nos» en $\mathbf{M} / \mathbf{P}$.

75 una de ellas] Escrito en el margen derecho. A causa de la encuadernación, «-as» no se percibe en la copia digitalizada del manuscrito proporcionada por la Real Biblioteca, pero pude confirmar su existencia al consultar el original.

${ }^{76}$ Se entiende «E [vos doy licencia e facultad e auctoridad] para que podades...». Véase arriba en el mismo párrafo: «E vos doy licencia e facultad e auctoridad para que, sin temor de Dios ni vergüença de las gentes, podades...». 


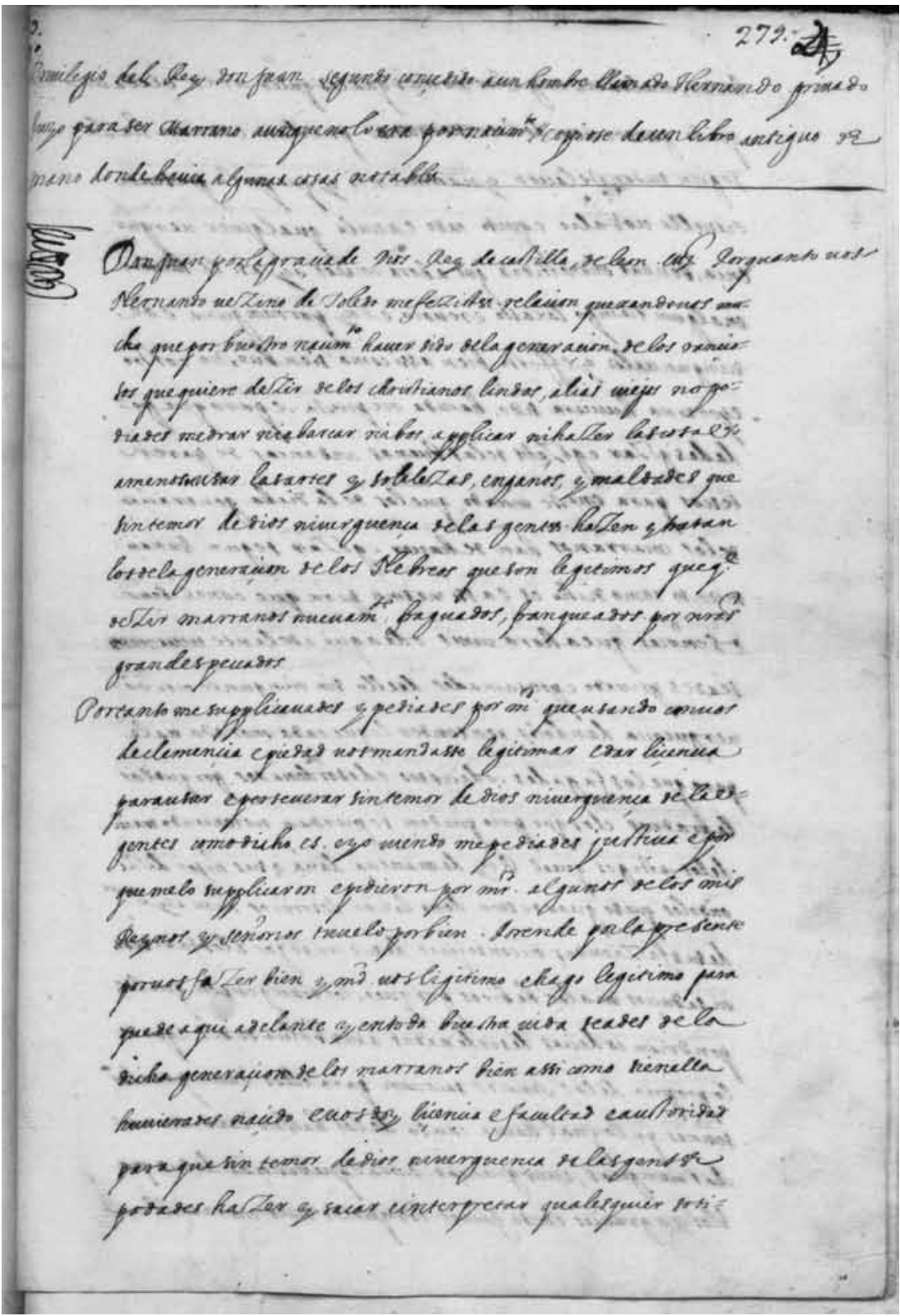

Fig. 4: (C) Real Biblioteca, Madrid, ms. 715, fol. 279r.

SEFARAD, vol. 72:2, julio-diciembre 2012, págs. 295-324. ISSN: 00037-0894. doi: 10.3989/sefarad.012.009 
para que podades gozar e gozedes de las buenas andanças de parentescos para en este mundo que los de la dicha generación de los marranos han de haver e gozar, según su nacimiento, como dicho es.

E assí mesmo para que con el señor o señores que ahora vivís, o de aquí adelante viviéredes, seades privado e presumades de ello sin ningún temor ni vergüença, dándoles a entender lo que cada moneda vale para que los fagades codiciosos e desordenados por que los labradores e los que poco pueden se pierdan, no teniendo memoria de los castigos que el rey de Mantua dava a sus hijos, diziéndoles que se guardassen de no hazer tesoreros ni mayordomos de sus faziendas ni consejeros de sus consejos a los fariseos ni saducíos ni a los hebreos, porque éstos eran gentes que los pondrían codicias desordenadas a sus boluntades, e que de lo proprio de los señores sacavan para ellos e aun para los señores. Por lo qual havía causa de los hazer caer en muchas menguas e vergüenças e malquerencias de sus pueblos e agravios e desafueros, los quales no es maravilla [fol. $280^{r} \mathbf{R}$ ] hazer estas y otras muchas cosas semejantes, pues a Nuestro Redemptor Jesú Christo la muerte tan sin causa trataron, haviéndoles fecho tantos bienes y mercedes como les fizo.

E assí mesmo podades alcançar e alcancedes con lisonjas, sotilezas, engaños simulados tanto provecho e interesse quanto alcança e alcançar podría cada uno de los de la dicha generación de los marranos. Por quanto es mi voluntad e merced, e cumple a nuestro servicio, que no seades menos ni de menor estado e condición ni de más vergüença que cada uno de ellos. E tengo por bien, y es mi merced ${ }^{77}$, que la divisa de buestras armas sean ${ }^{78}$ de aquí adelante jarras de Sancta María e ${ }^{79}$ flores de lis.

E otrosí que sin pena alguna podades dar a logro, renuevo e usura, e adorar la Torá ${ }^{80}$ e casar con buestras parientas, sean fijas, sobrinas o primas, e tener la oppinión malvada e intención que ellos tienen e mantienen, no creyendo ${ }^{81}$ lo que cree y tiene la Sancta Madre Iglesia ni los artículos de la fee ni el Credo, e creyendo que no ay más mundo [sino] ${ }^{82}$ de nacer y morir, e que podades guardar el sábado y trabajar el domingo e todas las otras fiestas communes generalmente mandadas guardar por la dicha Sancta Madre Iglesia.

77 merced] Tachado «uoluntad» y seguido por «merced», la lectura de $\mathbf{M} / \mathbf{P}$.

${ }^{78}$ sean] Cf. «sea» $\mathbf{M} / \mathbf{P}$.

79 e] MS: o. No es una oposición de jarras $o$ flores, sino una combinación de las dos imágenes; por lo tanto, «e» parece ser la lectura preferible. Cf. «y» en $\mathbf{M} / \mathbf{P}$.

${ }^{80}$ e adorar la Torá] Cf. «e adobar la casa de la Torá» en $\mathbf{M} / \mathbf{P}$.

${ }^{81}$ creyendo] Mal elaborada o corr. la «r»).

${ }^{82}$ El sentido de la conocida frase requiere «sino» (incluido por $\mathbf{M} / \mathbf{P}$ ). 
E por la presente mando a los dichos marranos que vos reciban en su ayuntamiento e confederación, e procuréis de haver qualquier officio de mí, assí de alcalde como de regimiento, para que en uno con ellos ayades e gozedes de los proprios de las cidades, villas e lugares de los mis reynos y señoríos donde assí fuéredes proveýdo, abatiendo a los christianos viejos [fol. $280^{v} \mathbf{R}$ ] con palabras sotiles e engañosas para que se maten unos a otros, usando con sus mugeres en tanto que ellos van a las guerras e a otras partes en mi servicio. E que bos muestren e ayuden a fazer todo lo que en esta mi carta es contenido, e que podades vos e los que de vos de aquí adelante vinieren, ser curas e oýr de penitencia a los christianos viejos para saber los secretos de ellos por que podades avisar e avisedes a los justicias marranos do estuviéredes de sus peccados e delictos que assí os huvieren ${ }^{83}$ confessado a fin que los echen presos por otra causa. E estonces los miembren aquel ${ }^{84}$ peccado e delicto que confessaron, diziéndoles e dándoles a entender que se halla por pesquisa o en otra qualquier manera les ayan sus officios, si los tuvieren, o sus faziendas, o sea causa de dormir con sus mugeres o fijas, si las tovieren, por salir de las cárceles.

Otrosí podáis ser boticario, phísico o cirujano para tratar e dar orden cómo passen desta vida a la otra los dichos christianos viejos para casar alguno de la dicha generación de los marranos con la muger por haver algún officio que de mí tienen, o su fija o fazienda, a fin que la alcance o aya alguno de la dicha generación de los marranos, según dicho es.

E assí mesmo para que vos, e los que de vos vinieren de aquí adelante, podades e puedan aprender ciencia hebrayca ${ }^{85}$ en la synoga, o en otra qualquier parte que la quisierdes oýr, e aprender e fazer buestro enterramiento en el fossario de los judíos, e comer carne en viernes e sábado, en Quaresma, quatro témporas e vigilias de Nuestra Señora ${ }^{86}$, e de $\left[\right.$ fol. $\left.281^{r} \mathbf{R}\right]$ todos los otros sanctos y sanctas de la corte celestial.

E podades entrar renegadamente en la iglesia e lugares sagrados sin devoción alguna e fingiéndola, llevando por libro de rezar el summario de buestras cuentas de las rentas en que tractáredes, con las rodillas en el suelo, dando a entender a los que os vieren rezáis los psalmos penitenciales, como lo hazen algunos de los de la dicha generación de los marranos.

Empero tengo por bien, y es mi merced y voluntad, no podáis fiar ni desafiar ni reptar ni ser reptado ni desafiado en fecho de armas porque no es de buestra

\footnotetext{
${ }^{83}$ huvieren] Toscamente escrito o corr. «hu».

84 aquel] Corr. de «a qual»».

85 hebrayca] Corr. de «hebraica».

86 Señora] ¿Corr. de $\left\langle\mathrm{s}^{\mathrm{ta}} »\right.$ ?
} 
ralea e por que no os puedan dezir «¿quién dio armas al marrano, sino vida baratera?» ${ }^{87}$.

E por la presente, de caso menor a mayor inclusive, de mi proprio motu e instancia e poder absoluto real de que en esta parte quiero usar e uso, vos perdono e remitto qualesquier juramentos falsos, mentiras e falsedades que dixéredes e affirmáredes en tanto que sean por lo que a vos e a buestros parientes e ynteresses buestros e suyos cumpliere, todavía manteniendo e levando la vía e orden que mantienen e lieban los otros de la dicha generación ${ }^{88}$ de los marranos e todo bien cumplidamente en guisa que vos no mengüe cosa e que podades tener e tengades dos caras: una ${ }^{89}$ para animar e lisongear, e otra para engañar e maltratar e mentir e falsear.

E assí mesmo que bos podades baptizar e bos baptizedes e tomar padrinos a quien quisiéredes, e para que después de baptizado bos podáis circuncidar o retajar según que ellos hazen, nombrándovos [fol. $\left.281^{v} \mathbf{R}\right]$ de aquello que sostienen e mantienen e entienden de sostener e mantener los de la dicha generación. E podades tomar appellido del linaje que quisiéredes e por bien tuviéredes, que en todo e por todo se guarde e cumpla la vía e orden que guardan los de la dicha generación de los marranos que se tornan christianos. E podades fazer e fagades todas e qualesquier solemnidades, obras e fablas e reverencias e demuestras falsas e fingidas ${ }^{90}$ que por fazer lo que a vos e a buestros interesses cumpliere e fueren necessarios e se requirieren fazer.

E por quanto es muy cierto e notorio que Pero Sarmiento, mi repostero mayor e assistente de mi casa e corte en todo e por todo, es capital enemigo de los marranos, es mi merced que él ni los de su linaje no conozcan de ningún pleyto ni pleytos ni causas algunas que a vos sean movidas o se os movieren en algún tiempo ni tenga en que entender en las cosas que os tocaren; antes os aya ${ }^{91}$ por encomendado para en los robos, daños e muertes e otros ${ }^{92}$ desastres que de aquí adelante ocurrieren y se trataren contra los dichos marranos, según que más

87 Aunque algo tangente al tema, véase F. SOYER, «Living in Fear of Revenge: Religious Minorities and the Right to Bear Arms in Fifteenth-Century Portugal», en Vengeance in the Middle Ages: Emotion, Religion and Feud, S. A. Throop y P. R. Hyams, eds. (Farnham, Surrey [GB]-Burlington, Vermont, 2010), 85-103.

88 generación] Mal elaborado «on».

${ }^{89}$ una] La escritura es muy pequeña y parte de la palabra se extiende dentro del margen, lo cual sugiere que es una añadidura posterior.

90 fingidas] Corr. la «g» de $\langle\mathrm{j}\rangle$.

91 aya] Quizá «ayan», puesto que el MS ostenta lo que podría ser una abreviatura sobre la segunda «a».

92 e otros + e otros. 
largamente refieren las profecías que en este caso fablan, e lo yo tengo ordenado e mandado.

E por esta mi carta e por su treslado signado, mando al príncipe don Henrrique, mi muy charo e amado hijo, so pena de mi paternal bendición, y al maestre de Santiago, mi condestable de Castilla, e a los duques, marqueses e condes, ricoshomes ${ }^{93}$, comendadores $\left[\right.$ fol. $282^{r} \mathbf{R}$ ] e alcaydes de todos mis castillos e casas fuertes e llanas de estos mis reynos e señoríos, e a los de mi casa y corte, oydores de mis audiencias e chancillerías, e al dicho Pero Sarmiento e a todos los del dicho su linaje, e a todos los concejos, corregidores, alcaldes, alguaziles e regidores, cavalleros, escuderos, officiales e homes buenos, e a otras qualesquier personas mis súbditos y naturales de qualquier estado o condición que sean, que os guarden e fagan guardar esta merced, perdón y privilegio que vos doy e fago, e que vos non vayan e passen ni consientan yr nin passar contra ello ni contra cosa alguna ni parte de ello, ahora ni en tiempo alguno ni por alguna manera, no embargante qualesquier leyes, fueros e derechos, ordenamientos, cartas e previlegios que los reyes mis predecessores cerca fizieron e ordenaron, e yo assí mesmo fiziere e ordenare de aquí adelante en contrario de lo en esta mi carta contenido ${ }^{94}$. Ca yo, de mi proprio motu ${ }^{95}$ e cierta ciencia e poder real absoluto de que en esta parte quiero usar, dispenso en todo ello y en cada una cosa de ello e parte dello con las cláusulas derogatorias en ella contenidas, e la abrogo ${ }^{96}$ e derogo e doy por ninguna e de ningún valor y effecto en quanto a esto atañe o atañer puede, bien assí como si nunca fuera ni fuesse fecho ni ordenado, por quanto es mi voluntad, e assí cumple a mi servicio e al bien común, tranquilidad, paz y sossiego destos mis reynos $\mathrm{y}^{97}$ [fol. $282^{v} \mathbf{R}$ ] señoríos e al buen regimiento e govierno de ellos.

Sobre lo qual, mando a el mi chanciller e notarios ${ }^{98}$ e otros qualesquier officiales que están en la tabla de mis sellos que vos den, passen e libren e sellen esta mi carta de previlegio e todas las otras mis cartas e sobrecartas que sobre esta voz fueren concedidas, las quales ${ }^{99}$ vos mando dar las más fuertes, bastantes e firmes que fueren menester e vos cumplieren e vos quisierdes e demandardes para que vos sea guardada esta mi carta de previlegio que vos doy e concedo según en esta mi carta es contenido con qualesquier vínculos, cláusulas e firmezas que vos quisierdes e pidierdes e para ello menester ovierdes. E yo por la presente

\footnotetext{
${ }^{93}$ ricoshomes] ¿Corr. la «c»?

94 contenido] Mal elaborada o corr. la primera «n».

95 motu] La «o» quizá comenzada como «t».

96 abrogo] MS: abrrogo.

$97 \mathrm{y}]$ Seguida por «y» al comienzo del fol. $282^{\mathrm{v}}$.

98 notarios] La «n» comenzada como otra letra.

99 quales] La «l» mal elaborada o corr.
} 


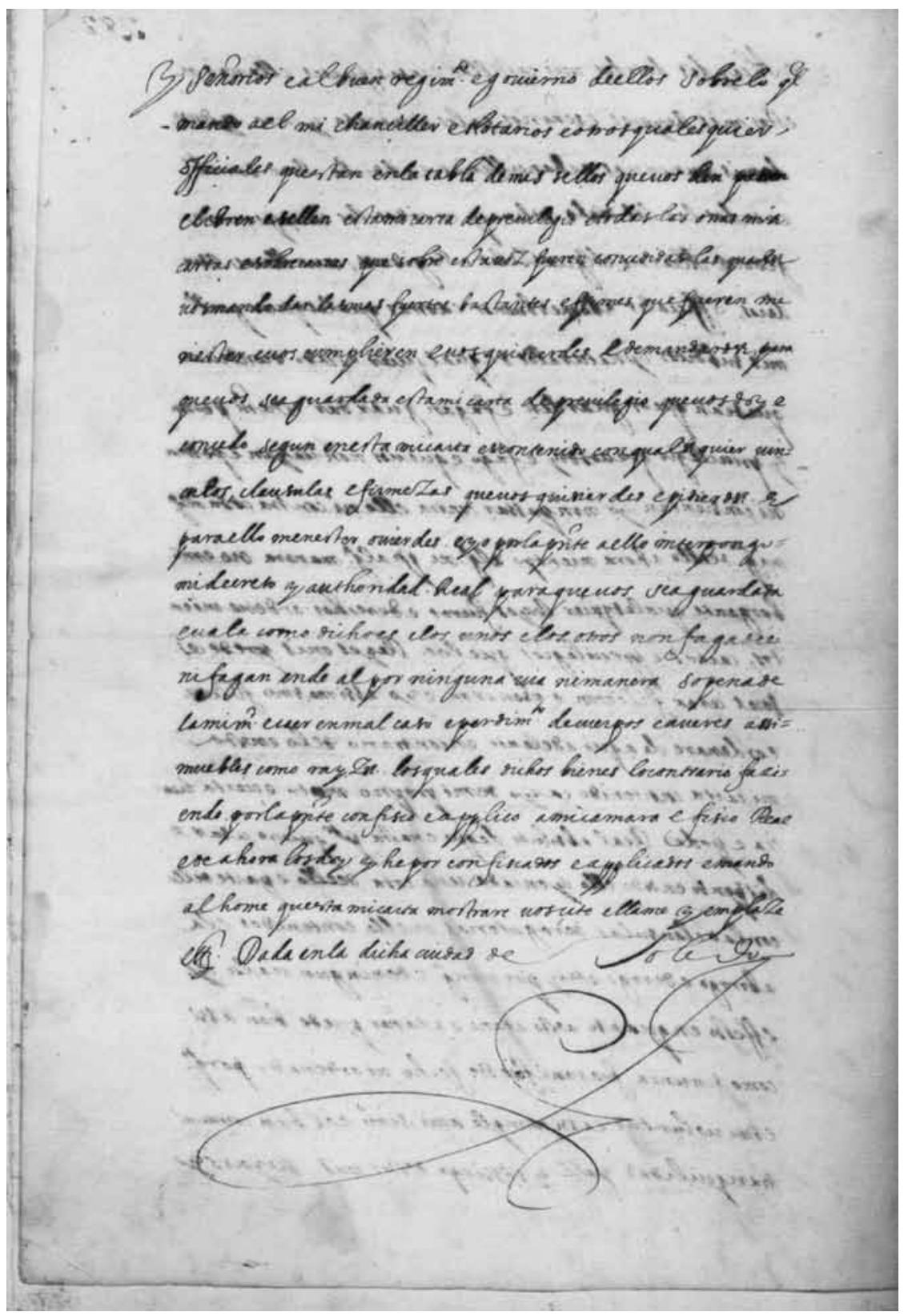

Fig. 5: (C) Real Biblioteca, Madrid, ms. 715, fol. 282v.

SEFARAD, vol. 72:2, julio-diciembre 2012, págs. 295-324. ISSN: 00037-0894. doi: 10.3989/sefarad.012.009 
a ello interpongo mi decreto y authoridad real para que vos sea guardada e vala como dicho es, e los unos e los otros non fagades ni fagan ende ál por ninguna vía ni manera so pena de la mi merced e caer en mal caso e perdimiento de cuerpos e averes, assí muebles como raýzes, los quales dichos bienes, lo contrario faziendo, por la presente confisco e applico a mi cámara e fisco real, e de ahora los doy y he por confiscados e applicados. E mando al home que esta mi carta mostrare, vos cite e llame y emplaze, etc. Dada en la dicha ciudad de Toledo ${ }^{100}$.

Recibido: 06/08/2012

Aceptado: 06/11/2012

${ }^{100}$ La mención explícita de Toledo al final de la obra le proporciona un toque de verosimilitud al privilegio y subraya la referencia al comienzo del texto de Hernando como «vezino de Toledo» (fol. $179^{\mathrm{r}}$ ). $\mathbf{M} / \mathbf{P}$ no señalan ninguna proveniencia concreta. 